\title{
BLOUNT DISEASE EVALUATION OF THE OPERATIVE TREATMENT WITHIN 2006-2014 IN DR. SOETOMO GENERAL HOSPITAL SURABAYA
}

\author{
Komang Agung Irianto Suryaningrat ${ }^{1 *}$, I.G.Ng. Dodo M. Ranuh ${ }^{2}$ \\ ${ }^{1}$ Department of Orthopaedic and Traumatology, Faculty of Medicine, Universitas Airlangga \\ / Dr Soetomo Hospital, Surabaya \\ ${ }^{2}$ Resident in Department of Orthopaedic and Traumatology, Faculty of Medicine, Universitas \\ Airlangga / Dr Soetomo General Hospital, Surabaya \\ *Correspondence: Komang Agung Irianto Suryaningrat, Department of Orthopaedic and \\ Traumatology, Faculty of Medicine, Universitas Airlangga / Dr Soetomo Hospital, Surabaya, \\ Jl. Mayjen Prof. Dr. Moestopo 6-7, Surabaya 60286 \\ E-mail: komang168@yahoo.com
}

\begin{abstract}
ABSTRAK
Latar Belakang: Penyakit blount merupakan gangguan pertumbuhan tulang sisi medial pada daerah epiphysis, dan metaphysis. Secara klinis didapatkan adanya angulasi varus dan internal rotasi pada tibia didaerah metaphysis.
\end{abstract}

Metode: Makalah ini mengevaluasi 2 kasus severe blount disease yang dilakukan operasi di RSU dr.Soetomo Surabaya pada tahun 2006 - 2014. Evaluasi dilihat dari sudut MDA (metadiaphyseal angle) pada sebelum dan sesudah operasi.

Hasil: Didapatkan hasil yang cukup signifikan dan memuaskan pada pasien dan orang tua yang telah dilakukan operasi. Terjadi pengurangan sudut MDA, pada pasien 1 sudut MDA sebelum operasi kanan 18 derajat dan kiri 40 derajat setelah operasi sudut MDA kanan 24 derajat dan kiri 10 derajat Sedangkan pada pasien 2 sudut MDA sebelum operasi kanan 32 derajat dan kiri 33 derajat, setelah operasi sudut MDA kiri sebesar 12 derajat.

Diskusi dan Kesimpulan: Pada penyakit blount yang severe masih ada harapan untuk dilakukan koreksi. Koreksi dapat dilakukan dengan melakukan osteotomi pada tulang tibia proksimal.

Kata kunci: penyakit blount, evaluasi blount, operasi

\section{ABSTRACT}

Background: Blount disease is a growth disturbance of the medial side of the proximal physeal of the tibia, epiphyseal and metaphyseal. Clinically this disease marked by varus angulation and internal rotation of the tibia on the metaphyseal area below knee.

Method: This paper evaluating 2 cases of blount disease treated surgically in Soetomo general hospital within 2006 - 2014. The evaluation based on MDA (meta-diaphyseal angle) pre and post operatively.

Result: Showed significant and satisfactory to patients and parents who have carried out the operation. A reduction in the angle of MDA, in first patients the MDA angle before surgery was 18 degrees on the right 40 degrees on the left, after surgery MDA was 24 degrees on the right, 10 degrees on the left. The second patient MDA before surgery was 32 degrees on the right and 33 degrees on the left, after the surgery MDA was 12 degrees on the left side, for the right side hasn't operated yet. 
Discussion and Conclusion: There is hope for correction on severe form of blount disease. Correction by performing a proximal tibia osteotomy on the affected bone.

Keywords: blount disease, blount evaluation, surgery

\section{PENDAHULUAN}

Penyakit Blount adalah gangguan pertumbuhan dari bagian medial pada fisis proksimal tibia, epifisis dan metafisis. ${ }^{1}$ Penyakit ini pertama kali diperkenalkan oleh Blount pada tahun 1937. ${ }^{1.2}$ Secara klinis, penyakit ini ditandai dengan angulasi varus dan rotasi ke arah internal dari tibia pada daerah metafisis di bawah lutut. ${ }^{3,4}$

Gambaran epidemiologi pada penyakit ini di Amerika Serikat, di antara jumlah populasi pada sekitar 1000 orang anak, terdapat 7 orang yang terkena penyakit Blount. Prevalensi dapat meningkat $2,5 \%$ pada suatu populasi yang beresiko tinggi seperti obesitas dan anak laki-laki kulit hitam. Klasifikasi secara klinis dapat dibedakan berdasarkan deformitas ekstremitas yang berkembang sebelum dan setelah usia 4 tahun. Thompson dan Carter mengklasifikasikan lebih lanjut late onset penyakit Blount sebagai tipe juvenil (onset pada usia 4-10 tahun) dan tipe adolesen (onset setelah usia 10 tahun). ${ }^{1-4}$
Penegakan diagnosis penyakit Blount berdasarkan anamnesis, pemeriksaan fisik, dan pemeriksaan radiologis. Pemeriksaan fisik meliputi status generalis dan status lokalis pada ekstremitas inferior terutama pada daerah lutut. Pemeriksaan radiologis yang dilakukan meliputi rontgen foto pada ekstremitas inferior proyeksi anteroposterior serta foto genu proyeksi anteroposterior dan lateral. ${ }^{1-4}$

Deformitas secara progresif dari penyakit ini menyebabkan instabilitas sehingga dapat terjadi gangguan dalam fungsi dan aktivitas sehari-hari, sehingga perlu dilakukan manajemen dengan baik. Manajemen pada penyakit Blount dapat dilakukan dengan cara konservatif atau operatif. Tujuan dari terapi penyakit blount adalah mengembalikan alignment ekstremitas bawah, sendi dan panjang kaki yang sama. Konservatif dapat dilakukan dengan observasi atau trial bracing, diberikan penggunaan orthotik bila deformitas meningkat. Tindakan operatif untuk manajemen penyakit Blount berupa osteotomy dapat 
dilakukan pada penyakit ini dengan derajat lanjut atau usia dewasa.

\section{LAPORAN KASUS}

\section{- Kasus 1}

Pasien I, laki-laki berusia 8 tahun. Datang ke rumah sakit dengan orang tuanya dengan keluhan utama kaki bengkok sejak pasien berusia 3 tahun dan semakin parah. Didapatkan obesitas pada pasien sejak usia 3 tahun, tidak didapatkan riwayat trauma, nyeri maupun kelemahan pada kedua ekstremitas bawah, tidak ada keluarga pasien yang pernah mengalami penyakit seperti pada pasien.

Pada pemeriksaan fisik ekstremitas inferior didapatkan adanya deformitas berbentuk o dengan sisi kiri tampak lebih bowing, range of motion ekstremitas bawah dalam batas normal.

Pada pemeriksaan radiologis didapatkan sudut MD kanan 18 derajat, sudut MD kiri 40 derajat dengan beaking pada metafisis pada kedua tibia bagian proksimal serta penebalan pada korteks medial pada kedua tibia.

Pasien didiagnosis sebagai Blount disease bilateral Langenskold VI.

Pasien telah dilakukan restorasi limb alignment dengan operasi double osteotomy dan epiphysiodesis dari tibia kiri. Dan dilanjutkan dengan pemberian knee brace hingga usia 18 tahun.
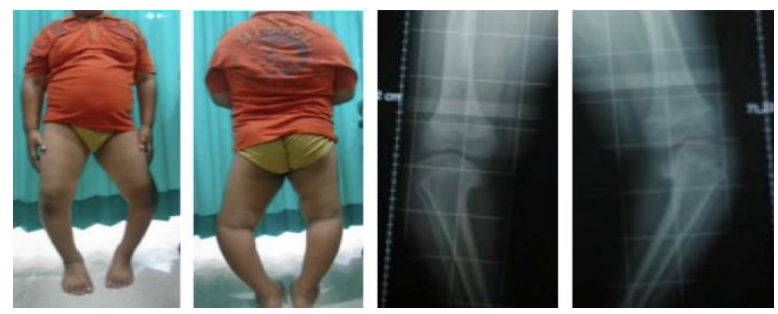

Gambar 1. Kondisi Pre Operatif Pasien I
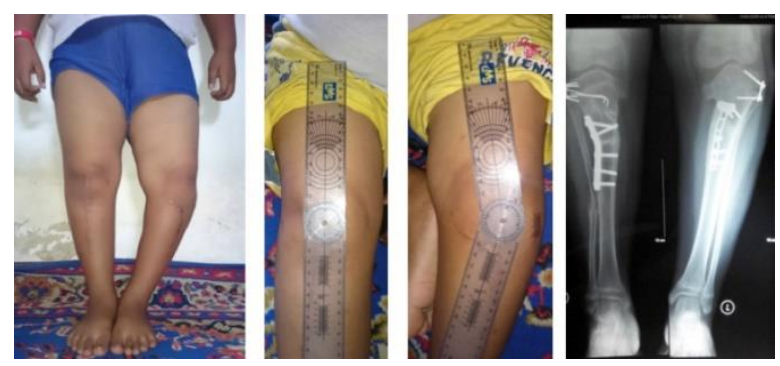

Gambar 2. Kondisi Post-Operasi Pasien I

Evaluasi pada pasien didapatkan sudut MDA kanan 24 derajat dan sudut MDA kiri 10 derajat. Pasien akan direncanakan operasi osteotomi proksimal tibia untuk mengkoreksi sudut MDA sebelah kanan dan saat ini masih menunggu antrian operasi.

\section{- Kasus 2}

Laki-laki berusia 8 tahun dengan kaki bengkok sejak pasien berusia 2 tahun yang makin memberat. Tidak didapatkan riwayat trauma, nyeri maupun kelemahan pada kedua kaki. Pasien didapatkan obesitas sejak kecil. 


\section{Laporan Kasus}

Vol 6 No. 2, Oktober 2017

ISSN 2460-8742

http://journal.unair.ac.id/journal-of-orthopaedic-and-traumatology-surabaya-media-104.html

Pada heteroanamnesis mengenai riwayat keluarga, tidak ada keluarga pasien yang pernah mengalami penyakit seperti pada pasien. Riwayat antenatal dan tumbuh kembang dalam batas normal.

Pada pemeriksaan fisik status lokalis regio extremitas inferior dextra dan sinistra, didapatkan deformitas berbentuk o dengan sisi kiri tampak lebih bowing, didapatkan genu varum kanan sebesar 38 derajat dan genu varum kiri 36 derajat, range of motion genu kiri serta kanan dalam batas normal.

Pada pemeriksaan radiologis didapatkan MDA kanan 32 derajat dan MDA kiri 33 derajat.

Pasien didiagnosis sebagai Blount disease Langenskold VI. Pasien telah dilakukan proksimal tibial osteotomi dan derotasi pada tibia sebelah kiri dan didapatkan MDA sebesar 12 derajat.
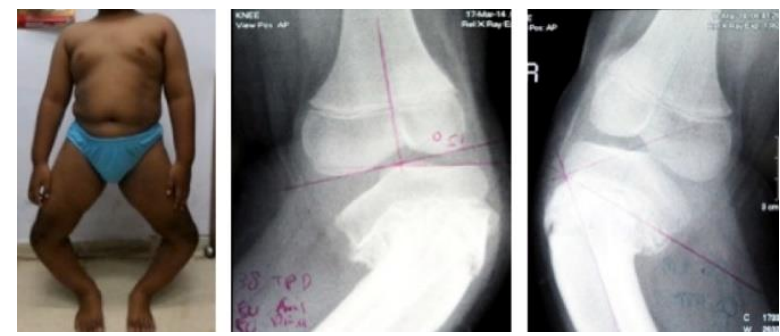

Gambar 3. Preoperatif Pasien 2
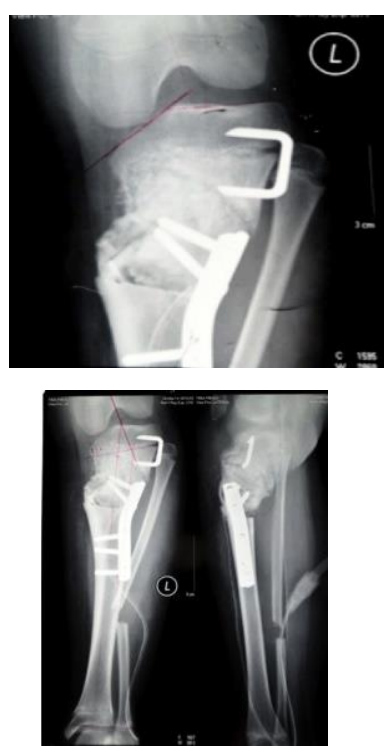

Gambar 4. Post Operasi Pasien 2

\section{Kasus 3}

Pasien anak B, laki-laki berusia 20 bulan dengan kaki kanan dan kiri bengkok. Kaki bengkok sejak pasien mulai berjalan pada usia 7 bulan dan bertambah parah. Tidak didapatkan riwayat trauma, nyeri maupun kelemahan pada kedua ekstremitas bawahnya, tidak ada keluarga pasien yang pernah mengalami penyakit seperti pada pasien. Dari riwayat antenatal dan tumbuh kembang pasien dalam batas normal.

$$
\text { Pada pemeriksaan fisik }
$$
didapatkan BMI 32,8\% (obesitas). Pada pemeriksaan extremitas inferior dextra dan sinistra, didapatkan adanya deformitas genu varum kanan dan kiri. Didapatkan genu varum dextra 12 
derajat, genu varum sinistra 14 derajat, dengan range of motion dalam batas normal.
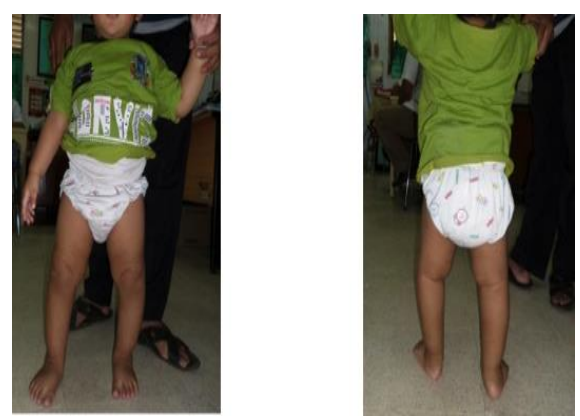

Gambar 5 Preoperatif Kasus 3

Pada pemeriksaan radiologis didapatkan MD angle kanan 10derajat, MD angle kiri 14derajat, dengan sloping medial epiphisis, beaking pada metafisis kedua tibia bagian proksimal dan penebalan korteks medial.

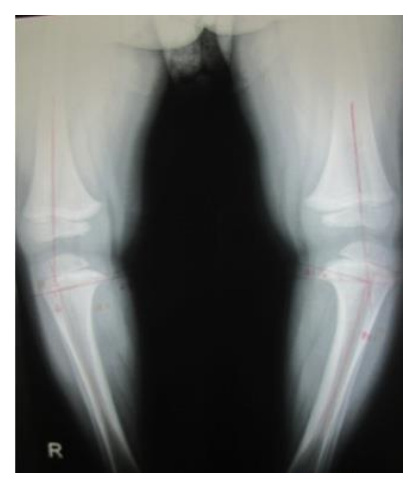

Gambar 6 Radiologis Preoperatif Kasus 3

Pasien di diagnosis sebagai infantile Blount Disease S Langenskold I-II.
Pasien dilakukan terapi konservatif dengan diet dan observasi. Dengan hasil adanya perbaikan MD angle kanan 10 derajat, MD angle kiri 11 derajat,

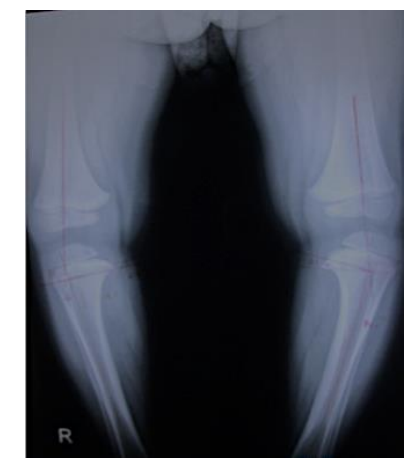

Gambar 21 Radiologis Post Terapi Kasus 3

\section{DISKUSI}

Di Amerika Serikat, prevalensi dari penyakit Blount ini dari seluruh populasi sekitar 1000 orang anak diantaranya terdapat 7 orang anak yang terkena penyakit Blount. Prevalensi dapat meningkat $2,5 \%$ pada suatu populasi yang beresiko tinggi yaitu obesitas dan anak laki-laki kulit hitam. ${ }^{1}$

Pada kasus pertama, anak laki laki berusia 8 tahun datang dengan keluhan utama kaki bengkok sejak pasien berusia 3 tahun. Pada saat keluhan tersebut diketahui, pasien mengalami obesitas. Gushue et al mempelajari pengaruh obesitas pada biomekanik sendi lutut. ${ }^{5}$ Dibandingkan 


\section{Laporan Kasus}

dengan anak yang memiliki berat badan normal, anak dengan kelebihan berat badan menunjukkan abduksi lutut internal dengan substansi puncak jauh lebih tinggi selama sikap awal dengan peningkatan isi kompartemen medial dari sendi lutut. Terdapat hubungan linier antara besarnya obesitas dan kelainan bentuk radiografi biplanar pada anak-anak dengan early onset penyakit Blount dan pada pasien dengan indeks massa tubuh $>40 \mathrm{~kg} / \mathrm{m}^{2}$ terlepas dari usia pada penyakit Blount. Meskipun memiliki indeks massa tubuh yang lebih rendah, anak dengan early onset penyakit Blount memiliki varus yang lebih parah dan kelainan procurvatum dari bagian proksimal tibia bila dibandingkan remaja dengan penyakit Blount. Dari anamnesis didapatkan riwayat berjalan pada usia 12 bulan. Pada pemeriksaan fisik didapatkan keadaan umum pasien dalam batas normal dengan berat badan $52 \mathrm{~kg}$ dan tinggi badan $128 \mathrm{~cm}$ dengan BMI $31,7 \%$, hal ini menunjukkan bahwa pasien mengalami obesitas. Hal ini merupakan faktor pendukung terjadinya Blount disease pada pasien ini. Analisa biomekanik menurut Cook sebagai etiologi genu vara, yaitu adanya stress yang berlangsung pada physis pada saat slance phase pada satu kaki. ${ }^{6}$ Gaya ini bekerja pada plateau medial. Pada varus $30^{\circ}$, kompresi stress pada bagian medial lempeng pertumbuhan tibia bertambah sebesar 7 kali. Pada anak dengan obesitas, lempeng pertumbuhan bagian medial ini mengalami stress yang lebih besar. $^{5}$

Golding et al menyatakan bahwa anak-anak di Afrika Barat memiliki insiden tibia vara relatif lebih tinggi dikarenakan 2 faktor, yaitu anak berjalan lebih awal dan adanya faktor hiperlaxity. ${ }^{7}$ Keadaan ini menyebabkan gerakan femoro-tibial yang berlebihan akibat gaya weight bearing yang mengalami perubahan dari arah tegak lurus menjadi oblique. Arah oblique ini memberi stress yang lebih besar pada physis bagian medial dibandingkan dengan lateral. Korteks bagian medial lebih pendek bila dibandingkan bagian lateral (hukum Heuter-Volkmann dan hukum Delpech) yang menentukan bentuk lutut varus seperti yang digambarkan pada gambar 4. ${ }^{1,7}$ Kessel juga menyatakan fibula tumbuh lebih panjang dibanding dengan tibia, bagian fibula proksimal terletak lebih ke posterolateral, sehingga varus dan rotasi tibia ke medial semakin progresif. ${ }^{6}$ Dari pemeriksaan fisik juga didapatkan status 


\section{Laporan Kasus}

Vol 6 No. 2, Oktober 2017

ISSN 2460-8742

http://journal.unair.ac.id/journal-of-orthopaedic-and-traumatology-surabaya-media-104.html

lokalis regio extremitas inferior dextra dan sinistra, pemeriksaan look didapatkan adanya deformitas berbentuk o dengan sisi kiri tampak lebih bowing. Pada pemeriksaan radiologis didapatkan sudut MD kanan 18 derajat, sudut MD kiri 40 derajat pada pasien didagnosis sebagai Blount disease Langenskold VI. Sesuai dengan teori bahwa pasien dengan Blount disease Langenskold VI pilihan terapi yang diberikan adalah terapi operatif. ${ }^{4}$ Pada pasien telah dilakukan double osteotomy bilateral (proximal tibia osteotomy + derotasi; osteotomy physis dan elevasi pada bulan april 2014. Dari hasil pengamatan setelah operasi didapatkan MDA kiri 11 derajat dan kanan 24 derajat. Pada pasien perlu dilakukan terapi operasi pada genu kanan untuk membantu memperbaiki restorasi dari genu varumnya.

\section{KESIMPULAN DAN SARAN}

\section{Kesimpulan}

Dari hasil pengamatan dapat disimpulkan bahwa penyakit ini dapat terjadi pada anak yang memiliki riwayat berjalan pertama kali pada usia dibawah 1 tahun serta pada anak yang mengalami obesitas. Keluhan dapat berupa kaki bengkok dan nyeri pada lutut. Tatalaksana dapat berupa konservatif maupun operatif tergantung dengan derajat penyakitnya.

Pada pasien dengan Blount langenskold I-II pada pengamatan ini dapat diterapi dengan cara konservatif. Dari hasil pengamatan didpatkan pasien dengan Blount Langenskold II yang tidak diberikan terapi namun terjadi perbaikan pada genu varumnya hal ini sesuai dengan penelitian dari shinohara. Pada pasien yang telah dilakukan terapi operatif, sebagian besar telah mengalami perbaikan limb alignment cukup baik dan orang tua merasa cukup puas dengan hasilnya. Pada pengamatan kasus seperti ini perlu dilakukan pendataan lebih baik mengenai identitas pasien agar pada pengamatan berikutnya dapat di telusuri lebih baik. Serta pengarsipan rekam medik rumah sakit agar lebih baik lagi.

\section{REFERENSI}

1. Sabharwal, S., 2000. Blount disease. $J$ Bone Joint Surg Am, 40(9), pp.1730-1731.

2. Langenskiöld, a.; riska, e.b., 1964. Tibia vara (osteochondrosis deformans tibiae): a survey of seventy-one cases. The journal of bone and joint surgery., 46-a(7), pp.1405-1420.

3. Hensinger RN. 1989. Angular deformities of the lower limbs in children. Iowa Ortho J; 9: 16-24.

4. Blount, WP., 1937. Tibia Vara, Osteochondrosis Deformans Tibiae. Journal of bone and joint surgery, 
XIX(1), pp.1-21. Available at: papers3://publication/uuid/520E971 3-AC1 A-4D5C-84B59C0EDBBA2DA8.

5. Gushue et al. 2005. Three Dimensional Knee Joint Biomechanics In Children: Effects Of Obesity. New York: 51st Annual Meeting of the Orthopaedic Research Society. Print.

6. Cook, S.D. et al., 1983. A biomechanical analysis of the etiology of tibia vara. Journal of pediatric orthopedics, 3(4), pp.449454.

7. Golding JSR, McNeil JD. 1970. Observation on the etiology of tibia vara. J Bone Joint Surg; 458: 93.

8. Mankin HJ. 2001. Genetic disorders, skletal dysplasias and malformations. In: Solomon L, Warwick DJ, Nayagam S. Apley's System of Orthopaedics and Fractures. $8^{\text {th }}$ ed. New York: Oxford University Press Publishers. p.13354.

9. Salter, Robert B. 1999. Textbook of disorder and injuries of the musculoskeletal system. $\quad 3^{\text {rd }}$ ed.Pennsylvania: $\quad$ Lippincott Wiliams \& Wilkins. p.364-5.

10. Levine, A. \& Drennan, J., 1982. Physiological Bowing and Tibia Vara. JBJS Am, 64-A(8), pp.11581163. 